\title{
Risk Factors of Autistic Spectrum Disorders (ASDs) among Egyptian children patients Attending Psychiatric Clinic of Postgraduate Childhood Studies Institute, Ain Shams University
}

\author{
Shaimaa S. Yousef *, Ghada E. Amin *, Olueya M. Abdel Baky ${ }^{* *}$, Samia I. El- \\ Damaty *. \\ *Department of Community, Environmental and Occupational medicine, Faculty of \\ medicine- Ain Shams University; ** Postgraduate Childhood Studies Institute - Ain \\ Shams University
}

Received : October $2015 \quad$ Accepted : January 2016

\begin{abstract}
Autism spectrum disorder (ASD) is characterized by difficulties in social interaction, verbal and nonverbal communication and repetitive behaviours. ASD is caused by a combination of genetic and environmental factors. Objective: to identify possible risk factors of ASD. Methods: The current study is a case-control study. We recruited 142 caregivers of the children to complete an interview questionnaire about risk factors for ASD. Seventy one (71) cases of autistic children were recruited from Postgraduate Childhood Studies Institute affiliated to Ain Shams University, and 71 normal children from outpatient pediatric clinics of the Ain Shams University hospital. Cases and controls were matched regarding age and sex. Results: Advanced paternal age at the time of conception, hypertension during pregnancy, postnatal hypoxia, positive family history of psychiatric diseases, and artificial feeding are risk factors for ASD. Also, folic acid supplementation during $1^{\text {st }}$ trimester is found to be protective from autism. Recommendations: Folic acid supplementation to the mother before pregnancy and at the first trimester of pregnancy (at least $600 \mathrm{mcg}$ per day) is mandatory.

Key words: Autism spectrum disorder, ASD, social interaction, communication, repetitive behaviors, advanced paternal age.

Corresponding author: Shaimaa S. Yousef Email: shaimaasamy37@yahoo.com, phone
\end{abstract}

\section{Introduction}

Autism spectrum disorder (ASD) and autism are both general terms for a group of complex disorders of brain development. These disorders are characterized, in varying degrees, by difficulties in social interaction, verbal and nonverbal communication and repetitive behaviors. The most obvious symptoms and signs of autism tend to emerge between 2 and 3 years of age. Early intervention with behavioral therapies can improve outcomes ${ }^{1}$. ASD affects over 3 million individuals in the United States and tens of millions worldwide $^{2}$. Autism statistics from the CDC reveal that around 1 in 68 American children have ASD. This increase is explained by improved diagnosis and public awareness. Studies also show that autism is four to five times more common among boys than girls. An estimated 1 out of 42 boys and 1 in 189 girls are diagnosed with autism in the United States ${ }^{3}$. In Egypt, there are no statistics showing the proportion of autistic children due to the considerable confusion between this group of children and a lot of different disabilities ${ }^{4}$.

The exact cause of autism is still unclear. It is now believed that the mechanism underlying autism etiology is most likely polygenic and that environmental factors may interact 
with genetic factors to increase risk ${ }^{5}$. The role of genetics in autism risk is suggested by the higher recurrence rate in siblings of children with autism than in siblings of normal children, and the greater concordance rate of monozygotic twins (36-96\%) as compared with same-sex dizygotic twins $(0-30 \%)^{6}$. A striking finding on ASD is the strong tendency for the risk to increase with the age of the parents, particularly the father, at the time of conception $^{5}$. Croen and his colleagues $(2007)^{7}$ found the relative risks of ASD associated with advanced maternal and paternal age to be 1.18 and 1.34 , respectively. Moreover, positive family history of psychiatric diseases is a significant risk factor for $\mathrm{ASD}^{8}$.

Prenatal factors increasing the risk for ASD are maternal bleeding during pregnancy, gestational diabetes ${ }^{9}$ and medications during pregnancy ${ }^{10}$. Also, studies have shown that folic acid demand is effective at reducing neural tube defect occurrence as Autism is a neurodevelopmental disorder that potentially originates during early pregnancy (first month) when folic acid is known to be critical $^{11}$. Furthermore, Abd Elhameed and his colleagues (2011) ${ }^{12}$ declared that the gestational hypertension was significantly higher in mothers of autistic children during pregnancy than in the control group. Moreover, AlAnsari and Ahmed (2013) ${ }^{13}$ found that caesarean section delivery may be associated with ASD in Bahrain. Neonatal factors which increase the risk for autism are like prematurity ${ }^{14}$ and fetal hypoxia ${ }^{15}$. On the other hand, CDC (2015) ${ }^{16}$ recommended that MMR vaccine is not responsible for the increase in the number of children with autism.

Although there is a significant number of researches on prenatal, perinatal, neonatal, and other risk factors of autism, the causal nature of these associations is still disputed due to several current methodological limitations of studies ${ }^{9}$.

The aim of this study was to identify possible risk factors of autistic spectrum disorder.

\section{Subjects and methods}

Study design and setting: A casecontrol study was conducted. The autistic children were recruited from Postgraduate Childhood Studies Institute affiliated to Ain Shams University, Egypt during the months of June, July, and August 2015. And the controls were recruited from outpatient pediatric clinics of Ain Shams University hospital, Egypt.

Study sample: The required sample size was 71 cases and 71 controls by using stata 10. Accordingly a total convenient sample of 142 was included in the study. Each group included 57 males $(80.3 \%)$ and 14 females (19.7\%). Their age ranged from 3 to 12 years (mean $6.4, \mathrm{SD} \pm 2.5$ years). Both cases and controls were matched regarding age and sex.

Children with ASD participating in the study have been diagnosed in the Postgraduate Childhood Studies Institute by the following: (1) Confirmation of diagnosis using DSM$\mathrm{V}$ criteria of autism ${ }^{1}$, i.e. Impairments of language, social skills, and restricted stereotyped interest or activity. (2) Assessment of mental age using Stanford-Binet intelligence scale, $4^{\text {th }}$ edition $^{17}$, to calculate the intelligence quotient (IQ). This test is used to measure the child cognitive abilities.

(3) Assessment of severity of autistic symptoms using childhood autism rating scale (CARS) ${ }^{18}$.

The control children were assessed by Childhood Autism Rating Scale (CARS) to exclude the presence of autistic features.

Study tool: Data was collected from all caregivers of children included in the 
study using a structured interview questionnaire which was written in Arabic and included all the following items:

Socio demographic data including: For Child: name, gender, age, birth order \& number of siblings. For Mother: age, marital status, level of education, occupation. For Father: age, level of education, occupation, smoking, consanguinity, income.

Mother History including: Antenatal history: age of mother during pregnancy of the child, induction of ovulation, presence of symptoms (bleeding during pregnancy, rubella, diabetes mellitus, hypertension, preeclampsia, convulsions), taking of medications (e.g. folic acid), exposure to radiation. Natal history: type of labor, breech presentation, place and time of birth. Postnatal history: birth weight, resuscitation, jaundice, admission to neonatal ICU, congenital anomalies.

\section{Child History including:}

Developmental history: Age of knowing mother, knowing father, sitting unassisted, walking unassisted, saying a word, saying a sentence, admission to school. Vaccination history: BCG, oral polio, DPT, hepatitis B, MMR vaccines. Nutritional history: Breast feeding or artificial feeding.

Family History including: Family history for any psychiatric diseases in the family.

Data management and analysis: The collected data was revised, coded, tabulated and introduced to a personal computer using Statistical package for Social Science (SPSS 20 for windows). Suitable statistical analysis was done according to the type of data obtained for each parameter. The significance level was set at $\mathrm{P}<0.05$.

Ethical consideration: Administrative approval was obtained from the manager of Postgraduate Childhood
Studies Institute. Informed consents were obtained from caregivers including objectives, benefits, risks of the study and confidentiality of the individual data was assured.

\section{Results}

Table (1) shows that a statistically significant difference regarding education of mothers, age of fathers at conception and education of fathers, family income. Regarding family history, there was a statistically significant difference between cases and controls regarding family history of psychiatric diseases. Table (2) shows that a statistically significant difference between cases' and controls' mothers regarding hypertension during pregnancy and folic acid supplementation during $1^{\text {st }}$ trimester of pregnancy. All mothers hadn't history of eclampsia, rubella infection, smoking or radiation during pregnancy. Table (3) shows that no statistically significant difference between cases' and controls' mothers regarding their natal history. Table (4) shows that a statistically significant difference between cases and controls regarding postnatal hypoxia, admission to NICU, period of admission, cause of admission and artificial feeding. Table (5) shows that after applying logistic regression model, the variables that affected ASD were positive family history of psychiatric diseases $(\mathrm{OR}=7.45)$, postnatal hypoxia $(\mathrm{OR}=$ 4.64) and folic acid supplementation during $1^{\text {st }}$ trimester of pregnancy $(\mathrm{OR}=0.199)$.

\section{Discussion}

There is agreement amongst all professionals that autism is one of the most puzzling diseases. It is a neurodevelopmental disorder characterized by impairments in social and communication skills as well as restricted, repetitive, and stereotyped 
patterns of behavior and movement. Its prevalence has surged in recent years ${ }^{1}$. The findings of the current study showed that, mean age of studied children is 6.4years old, This finding is in agreement with Elwardany and her colleagues (2013) ${ }^{19}$ at Assiut City.

The present study showed that, most of children were males $(80.3 \%)$. The findings of the present study are consistent with CDC (2014) ${ }^{3}$ who declared that the estimated number of male to female children with ASD is approximately five times higher in boys than girls.

The current study showed that high paternal age (father $\geq 35$ years) during pregnancy was found in $38.1 \%$ of autistic children in comparison with $15.5 \%$ of control group and the difference was statistically significant. Also the current study showed that high maternal age (mother $\geq 35$ years) during pregnancy was found in $5.6 \%$ of autistic children in comparison of none of controls and the difference was statistically insignificant.

These results was in agreement with Reichenberg and his colleagues (2006) ${ }^{20}$ who illustrated that there was an association between advancing paternal age and risk of ASD. They concluded that offspring of 40 years men or older were 5.75 times more likely to have ASD compared with offspring of men younger than 30 years, while advancing maternal age showed no association with ASD after adjusting for paternal age.

Regarding education, the current study showed that $(64.8 \%)$ of fathers and $(56.3 \%)$ of mothers of autistic children had university level of education; compared with (31\%), (29.6\%) for fathers and mothers of control group respectively. This may be due to the educated parents had awareness and good observation for any signs or change of child. These findings were consistent with Elwardany et al. $(2013)^{19}$.

Regarding the family income, $(25.4 \%)$ of cases compared with $(11.3 \%)$ of controls, their income was ranging between 3000 to $5000 \mathrm{LE}$, which was statistically significant. This may be due to high education among parents of autistic children.

The present study illustrated that (29.6\%) of parents had consanguinity degree. This study agreed with AlSalehi and his colleagues (2012) ${ }^{21}$ in Saudi Arabia, but disagreed with ElBaz and her colleagues (2011) ${ }^{22}$. On the other hand, Sasanfar and his colleagues (2010) ${ }^{23}$ reported that consanguinity had no role in a study done on the Iranian population.

According to family history of psychiatric diseases; the results of the present study showed that; $(18.3 \%)$ of autistic children had family history of psychiatric diseases compared with $(2.8 \%)$ of control group, this difference was statistically significant. This finding was in agreement with Sullivan and his colleagues $(2012){ }^{8}$ who found that presence of schizophrenia or bipolar disorder in first-degree relatives was a consistent and significant risk factor for ASD.

As regards prenatal factors; the present study found that cases' mothers had induction of ovulation more than controls' mothers and the difference was statistically insignificant. This finding was inconsistent with Hvidtjørn and his colleagues (2010) ${ }^{24}$ who conducted a follow-up study in Denmark to assess the risk of ASD in children born after assisted conception. The difference may be due to different study populations and cultures.

The current study revealed that cases' mothers had hypertension during pregnancy more than controls' mothers and the difference was statistically significant. This result disagreed with El-Baz and his colleagues (2011) ${ }^{22}$ 
who revealed that no significant difference was found between cases and controls as regards hypertension during pregnancy.

This study showed that there were no statistically significance difference between cases' and controls' mothers regarding bleeding during pregnancy and gestational diabetes and autism. But, Gardner and his colleagues (2011) ${ }^{5}$ reported that there was an association between maternal bleeding during pregnancy and gestational diabetes and autism. These differences might be explained by different study populations. All mothers of studied children hadn't history of rubella infection during pregnancy, eclampsia, smoking, exposure to radiation during pregnancy.

According to folic acid supplementation, $(80.3 \%)$ of cases' mothers compared with $(94.4 \%)$ of controls' mothers have received folic acid during $1^{\text {st }}$ trimester of pregnancy, which was statistically significant. This finding was in agreement with Schmidt and his colleagues (2012) ${ }^{11}$ who reported that folic acid intake was significantly greater for mothers of typically developing children than for mothers of autistic children with ASD. This finding is supported by the odds ratio $(<1)$, resulted by logistic regression model for the factors affecting ASD among studied groups, which means that folic acid supplementation in the $1^{\text {st }}$ trimester is protective from ASD.

As regards natal factors, ceserian section delivery was (36.6\%) in both groups, which was a statistically insignificant. This results was consistent with El-Sawy (2011) ${ }^{10}$ who found that $(59.1 \%)$ of cases' mothers and $(43.2 \%)$ of controls' mothers delivered by caesarean section, yet it seemed to have no impact on the etiology of autism. But El-Baz and her colleagues (2011) ${ }^{22}$ reported that ceserian section was statistically significantly increased in mothers of autistic patients. This difference may be due to different causes of CS which may be lead to neonatal hypoxia.

As regards place of birth, most of mothers of cases and controls were delivered in hospital or special clinic, and the difference was statistically insignificantly. This finding is expected due to increased awareness of mothers to deliver under supervision of medical staff for better monitoring the progress in labor and checkup the baby after birth.

As regards prematurity, (9.9\%) of cases versus $(4.2 \%)$ of controls were delivered less than 37 weeks, this difference was statistically insignificantly. This finding was consistent with El-Baz and her colleagues $(2011)^{22}$ and also with Visser and his colleagues $(2013)^{15}$.

As regards birth weight, (15.5\%) of cases versus $(11.3 \%)$ of controls had low birth weight at birth, which was statistically insignificant. This finding is in agreement with Visser and his colleagues (2013) ${ }^{15}$. On the other hand, El-Baz and her colleagues (2011) ${ }^{22}$ who reported that low birth weight had statistically significant effect for ASD. The difference may explained by the subjective reporting of the birth weight by the caregivers of children.

As regards postnatal hypoxia, (21.1\%) of cases versus $(4.2 \%)$ of controls were exposed to postnatal hypoxia, and the difference was statistically significant. Therefore, regarding cause of admission to Neonatal Intensive Care (NICU), hypoxia represented $(16.9 \%)$ of causes of admission to NICU among cases versus $(4.2 \%)$ of controls. This finding is consistent with Visser and his colleagues $(2013)^{15}$ and El-Baz and her colleagues $(2011)^{22}$.

The current study showed that there was no significant effect of 
Hyperbilirubinemia for ASD which was consistent with El-sawy (2011) ${ }^{10}$. The present study shows that, equal percent of both groups (4.2\%) had history of congenital anomalies, which was in agreement with Visser and his colleagues $(2013)^{15}$.

The current study showed that (25.4\%) of cases versus $(8.5 \%)$ of controls were admitted to NICU after birth, the difference was statistically significant. This explained as the primary cause of admission was postnatal hypoxia, which is distressing sign for the child, so mostly needs admission to NICU as a life saving measure. Regarding period of admission to NICU, the cases were admitted more than controls and the difference was also statistically significant for autistic children. This explained as period of admission is according to the severity of condition. As regards nutritional history, (31\%) of cases versus $(15.5 \%)$ of controls had artificial feeding, which was statistically significant. This results were in agreement with Schultz and his colleagues $(2006)^{25}$ who declared that, babies who were not breastfed had a four times higher risk of autism than babies who were breastfed due to essential fatty acids are necessary for the proper development of the brain and nervous system, are present in breast milk.

Logistic regression model of the factors affected ASD among studied groups $(\mathrm{N}=142)$ showed that folic acid supplementation during $1^{\text {st }}$ trimester of pregnancy $(\mathrm{OR}=0.21,95 \% \mathrm{CI}=0.06$, 0.71) was protective, while positive family history of psychiatric diseases $(\mathrm{OR}=8.26,95 \% \mathrm{CI}=1.71,39.98)$ and postnatal hypoxia $(\mathrm{OR}=4.79,95 \% \mathrm{CI}=$ $1.22,18.83)$, were significant risk factors for ASD.

Conclusion: Folic acid supplementation during $1^{\text {st }}$ trimester of pregnancy is protective from ASD, positive family history of psychiatric diseases and postnatal hypoxia, were significant risk factors for ASD. ASD was also significantly associated with advanced paternal age at conception, hypertension during pregnancy, admission to NICU, duration of admission to NICU and artificial feeding.

Recommendations: Increase public awareness about the risk factors and early signs of ASD. Folic acid supplementation before pregnancy and at the first trimester of pregnancy and/or eating a diet rich in folic acid (at least $600 \mathrm{mcg}$ per day) is mandatory for prevention of ASD. All children should be screened with standardized developmental tools at specific intervals at the 9-18-24-30 months for early detection of ASD. Proper management of autistic children including behavior, educational, cognitive and pharmacotherapy through expanding and fortifying the autism specialized rehabilitation centers to improve the lives of those children.

\section{References}

1. American Psychiatric Association : Diagnostic and statistical manual of mental disorders, 5th ed., Text Revision (DSM V), Washington, DC, 2013.

2. Autism Speaks: What is Autism? Accessed on December, 12, 2015 Available on https://www.autismspeaks. org/what-autism

3. Centers for Disease Control and Prevention: Prevalence of autism spectrum disorder among children aged 8 Years, Autism and Developmental Disabilities Monitoring Network, 11 sites, United States, MMWR 2014; 63 (No. SS 2):1-21.

4. Abdel Hameed MI: The Effectiveness of an Educational Training Program for Autistic Children's Mothers in the Development of Some of the Daily-Life Skills in their Children. Journal of American Science 2015; 11 (2): 45-61.

5. Gardener H, Spiegelman D \& Buka SL: Perinatal and Neonatal Risk Factors for 
Autism: A Comprehensive Meta-analysis. J. Pediatrics. 2011; 128(2):344-355.

6. Zhang X, Lv C, Tian J, et al.: Prenatal and Perinatal Risk Factors for Autism in China. Journal of Autism and Developmental Disorders 2010; 40 (11): 1311-1321.

7. Croen LA, Daniel V, Najjar DV, et al.: Maternal and Paternal Age and Risk of Autism Spectrum Disorders. Arch Pediatr Adolesc Med. 2007; 161(4):334-340.

8. Sullivan PF, Magnusson C, Reichenberg A, et al.: Family History of Schizophrenia and Bipolar Disorder as Risk Factors for Autism. Arch Gen Psychiatry 2012; 69(11):1099-1103.

9. Gardener H, Spiegelman D\& Buka SL: Prenatal risk factors for autism: comprehensive meta-analysis. $\mathrm{Br} \quad \mathrm{J}$ Psychiatry.2009; 195(1):7-14.

10. El Sawy MA, Awadalla HI, Mohamed RR, et al.: (2011). International Journal of Psychology and Counseling 2011; 3(8): 130-136.

11. Schmidt RJ, Tancredi DJ, Ozonoff S, et al.: Maternal periconceptional folic acid intake and risk of autism spectrum disorders and developmental delay in the CHARGE (CHildhood Autism Risks from Genetics and Environment) case-control study. Am J Clin Nutr. 2012; 96(1): 8089.

12. Abd Elhameed MA, Abd Elbaky AO \& Kamel EA: A Controlled Study of the Risk Factors and Clinical Picture of Children with Autism in an Egyptian Sample. The Egypt Journal of Neurology, Psychiatry and Neurosurgery2011; 48 (3): 271- 276.

13. Al- Ansari AM \& Ahmed MM: Epidemiology of autistic disorder in Bahrain: prevalence and obstetric and familial characteristics. East Mediterranean Health J. 2013; 19 (9):769774.

14. Kuzniewicz, M W, Wi S, Qian Y, et al.: Prevalence and neonatal factors associated with autism spectrum disorders in preterm infants. The Journal of Pediatrics 2014; 164(1): 20-25.

15. Visser JC, Rommelse N,Vink L, et al.: Narrowly Versus Broadly Defined Autism Spectrum Disorders: Differences in Preand Perinatal Risk Factors. Journal of
Autism and Developmental Disorders 2013; 43(7): 1505-1516.

16. Centers for Disease Control and Prevention (2015 a): Measles, Mumps, and Rubella (MMR) Vaccine Safety Studies, Accessed on December 5, 2015. From http://www.cdc.gov/vaccinesafety/vaccine $\mathrm{s} / \mathrm{mmr} / \mathrm{mmr}$-studies.html

17. Stanford-Binet International Scale: 4 th ed., 2 years to adult, useful for handicapped children. 1986

18. Schopler E, Reichler RJ \& Renner BR: the childhood autism rating scale (CARS): for diagnostic screening and classification of autism. New York: Irvington 1988.

19. Elwardany S, Ibrahim H, Askar G, et al.: Risk factors for Autistic Spectrum Disorders at Assiut City. Journal of Education and Practice 2013; 4 (28): 147 157.

20. Reichenberg A, Gross R, Weiser M, et al.: Advancing paternal age and autism. Arch Gen Psychiatry 2006; 63(9):10261032.

21. Al-Salehi SM, Al-Hifthy EH \& Ghaziuddin M: Autism in Saudi Arabia: Presentation, Clinical Correlates and Comorbidity, University of Michigan Medical Center, Journal of Transcultural Psychiatry 2012; 49(5):110-120.

22. El-Baz F, Ismael NA \& Nour El-Din SM: Risk factors for autism: An Egyptian study. The Egyptian Journal of Medical Human Genetics 2011; 12: 31-38.

23. Sasanfar R, Haddad SA, Tolouei A, et al. Paternal age increases the risk for autism in an Iranian population sample. Molecular Autism 2010; 1(1): 1-10.

24. Hvidtjørn D, Grove J, Schendel D, et al.: Risk of autism spectrum disorders in children born after assisted conception: a population-based follow-up study. J Epidemiol Community Health 2011; 65: 497- 502

25. Schultz S, Klonoff- Cohen H, Wingard D, Akshoomoff N, Macera C, Ji $M$ and Bacher C: Breastfeeding, infant formula supplementation, and Autistic Disorder: the results of a parent survey. International Breastfeeding Journal 2006; 1(1): 16. 
Table (1): Socio- demographic characteristics of studied groups and family history:

\begin{tabular}{|c|c|c|c|c|c|c|}
\hline \multirow[t]{2}{*}{ Item } & & \multicolumn{2}{|c|}{$\begin{array}{l}\text { Cases } \\
\mathrm{N}=71\end{array}$} & \multicolumn{2}{|c|}{$\begin{array}{c}\text { Controls } \\
\mathrm{N}=71\end{array}$} & \multirow{2}{*}{$\begin{array}{c}\text { P- } \\
\text { value }\end{array}$} \\
\hline & & $\mathbf{N}$ & $\%$ & $\mathbf{N}$ & $\%$ & \\
\hline \multirow[t]{3}{*}{ Marital status } & Married & 67 & 94.4 & 66 & 93 & \multirow[t]{3}{*}{0.555} \\
\hline & Divorced & 4 & 5.6 & 3 & 4.2 & \\
\hline & Widow & 0 & 0 & 2 & 2.8 & \\
\hline \multirow[t]{6}{*}{ Education of mother } & Illiterate & 3 & 4.2 & 12 & 16.9 & \multirow[t]{6}{*}{ 0.003* } \\
\hline & $\begin{array}{l}\text { Read and } \\
\text { Write }\end{array}$ & 0 & 0 & 4 & 5.6 & \\
\hline & Primary & 1 & 1.4 & 3 & 4.2 & \\
\hline & Preparatory & 7 & 9.9 & 10 & 14.1 & \\
\hline & Secondary & 20 & 28.2 & 21 & 29.6 & \\
\hline & University & 40 & 56.3 & 21 & 29.6 & \\
\hline \multirow{5}{*}{$\begin{array}{l}\text { Age of mother at conception of autistic } \\
\text { child in years }\end{array}$} & $<20$ & 4 & 5.6 & 11 & 15.5 & \multirow[t]{5}{*}{0.101} \\
\hline & 20- & 28 & 39.4 & 29 & 40.8 & \\
\hline & $25-$ & 25 & 35.2 & 24 & 33.8 & \\
\hline & 30- & 10 & 14.1 & 7 & 9.9 & \\
\hline & 35 or more & 4 & 5.6 & 0 & 0 & \\
\hline \multirow{6}{*}{$\begin{array}{l}\text { Education of } \\
\text { Father }\end{array}$} & Illiterate & 3 & 4.2 & 15 & 21.1 & \multirow[t]{6}{*}{ 0.000* } \\
\hline & $\begin{array}{l}\text { Read and } \\
\text { Write }\end{array}$ & 1 & 1.4 & 1 & 1.4 & \\
\hline & Primary & 1 & 1.4 & 0 & 0 & \\
\hline & Preparatory & 4 & 5.6 & 6 & 8.5 & \\
\hline & Secondary & 16 & 22.5 & 27 & 38 & \\
\hline & University & 46 & 64.8 & 22 & 31 & \\
\hline \multirow{3}{*}{$\begin{array}{l}\text { Age of father at conception of autistic } \\
\text { child in Years** }\end{array}$} & $<\mathbf{3 0}$ & 21 & 29.6 & 35 & 49.3 & \multirow[t]{3}{*}{$0.006 *$} \\
\hline & 30- & 23 & 32.4 & 25 & 35.2 & \\
\hline & $\geq 35$ & 27 & 38.1 & 11 & 15.5 & \\
\hline \multirow{3}{*}{$\begin{array}{l}\text { Income/ month } \\
\text { (in Egyptian pounds) }\end{array}$} & $<1200$ & 14 & 19.7 & 34 & 47.9 & \multirow[t]{3}{*}{ 0.001* } \\
\hline & 1200- & 39 & 54.9 & 29 & 40.8 & \\
\hline & 3000- 5000 & 18 & 25.4 & 8 & 11.3 & \\
\hline \multirow[t]{2}{*}{ Consanguinity } & No & 50 & 70.4 & 50 & 70.4 & \multirow[t]{2}{*}{1.00} \\
\hline & Yes & 21 & 29.6 & 21 & 29.6 & \\
\hline \multirow[t]{2}{*}{ Family history of psychiatric diseases } & No & 58 & 81.7 & 69 & 97.2 & \multirow[t]{2}{*}{$0.003 *$} \\
\hline & Yes & 13 & 18.3 & 2 & 2.8 & \\
\hline
\end{tabular}

"Statistically significant, ** No fathers of autistic children were below 25 years at time of conception. 
Table (2): Comparison between cases and controls as regard Antenatal history of the mother:

\begin{tabular}{|c|c|c|c|c|c|c|}
\hline & \multirow[t]{2}{*}{ Item } & \multicolumn{2}{|c|}{$\begin{array}{l}\text { Cases } \\
N=71\end{array}$} & \multicolumn{2}{|c|}{$\begin{array}{c}\text { Controls } \\
\mathrm{N}=71\end{array}$} & \multirow[t]{2}{*}{ P-value } \\
\hline & & $\mathbf{N}$ & $\%$ & $\mathbf{N}$ & $\%$ & \\
\hline \multirow[t]{2}{*}{ Induction of ovulation } & No & 60 & 84.5 & 66 & 93.0 & \multirow[t]{2}{*}{0.111} \\
\hline & Yes & 11 & 15.5 & 5 & 7.0 & \\
\hline \multirow[t]{2}{*}{ Bleeding } & No & 64 & 90.1 & 65 & 91.5 & \multirow[t]{2}{*}{0.77} \\
\hline & Yes & 7 & 9.9 & 6 & 8.5 & \\
\hline \multirow[t]{2}{*}{ Gestational DM } & No & 69 & 97.2 & 67 & 94.4 & \multirow[t]{2}{*}{0.68} \\
\hline & Yes & 2 & 2.8 & 4 & 5.6 & \\
\hline \multirow{2}{*}{$\begin{array}{l}\text { Hypertension during } \\
\text { pregnancy }\end{array}$} & No & 59 & 83.1 & 67 & 94.4 & \multirow[t]{2}{*}{ 0.034* } \\
\hline & Yes & 12 & 16.9 & 4 & 5.6 & \\
\hline \multirow[t]{2}{*}{ Preeclampsia } & No & 65 & 91.5 & 70 & 98.6 & \multirow[t]{2}{*}{0.12} \\
\hline & Yes & 6 & 8.5 & 1 & 1.4 & \\
\hline \multirow{2}{*}{$\begin{array}{l}\text { Folic Acid } \\
\text { supplementation }\end{array}$} & No & 14 & 19.7 & 4 & 5.6 & \multirow[t]{2}{*}{$0.012 *$} \\
\hline & Yes & 57 & 80.3 & 67 & 94.4 & \\
\hline
\end{tabular}

*Statistically significant

Table (3): Comparison between cases and controls as regard natal history of the mothers:

\begin{tabular}{|c|c|c|c|c|c|c|}
\hline \multirow[t]{2}{*}{ Item } & & \multicolumn{2}{|c|}{$\begin{array}{l}\text { Cases } \\
\mathrm{N}=71\end{array}$} & \multicolumn{2}{|c|}{$\begin{array}{c}\text { Controls } \\
N=71\end{array}$} & \multirow[t]{2}{*}{ P-value } \\
\hline & & $\mathbf{N}$ & $\%$ & $\mathbf{N}$ & $\%$ & \\
\hline \multirow[t]{2}{*}{ Type of labor } & VD & 45 & 63.4 & 45 & 63.4 & \multirow[t]{2}{*}{1.00} \\
\hline & CS & 26 & 36.6 & 26 & 36.6 & \\
\hline \multirow[t]{4}{*}{ Place of birth } & Home & 1 & 1.4 & 4 & 5.6 & \multirow{4}{*}{0.055} \\
\hline & Hospital & 59 & 83.1 & 47 & 66.2 & \\
\hline & Special Clinic & 9 & 12.7 & 19 & 26.8 & \\
\hline & Others (in car) & 2 & 2.8 & 1 & 1.4 & \\
\hline \multirow[t]{3}{*}{ Time of birth } & Full Term & 64 & 90.1 & 65 & 91.5 & \multirow{3}{*}{0.12} \\
\hline & Preterm & 7 & 9.9 & 3 & 4.2 & \\
\hline & Post Term & 0 & 0 & 3 & 4.2 & \\
\hline
\end{tabular}


Table (4): Comparison between cases and controls as regard neonatal history:

\begin{tabular}{|c|c|c|c|c|c|c|}
\hline \multirow[t]{2}{*}{ Item } & & \multicolumn{2}{|c|}{$\begin{array}{l}\text { Cases } \\
\mathrm{N}=71\end{array}$} & \multicolumn{2}{|c|}{$\begin{array}{c}\text { Controls } \\
N=71\end{array}$} & \multirow[t]{2}{*}{ P-value } \\
\hline & & $\mathbf{N}$ & $\%$ & $\mathbf{N}$ & $\%$ & \\
\hline \multirow[t]{4}{*}{ Birth WT } & VLBW (< 1500 gm.) & 2 & 2.8 & 0 & 0 & \multirow{4}{*}{0.196} \\
\hline & LBW (1500 - 2500 gm.) & 11 & 15.5 & 8 & 11.3 & \\
\hline & NBW (2500 - 4000gm.) & 51 & 71.8 & 60 & 84.5 & \\
\hline & HBW (> 4000 gm.) & 7 & 9.9 & 3 & 4.2 & \\
\hline \multirow[t]{2}{*}{ Hypoxia } & No & 56 & 78.9 & 68 & 95.8 & \multirow{2}{*}{$0.002 *$} \\
\hline & Yes & 15 & 21.1 & 3 & 4.2 & \\
\hline \multirow{2}{*}{$\begin{array}{l}\text { Admission to } \\
\text { NICU }\end{array}$} & No & 53 & 74.6 & 65 & 91.5 & \multirow{2}{*}{$0.007 *$} \\
\hline & Yes & 18 & 25.4 & 6 & 8.5 & \\
\hline \multirow{3}{*}{$\begin{array}{l}\text { Period of } \\
\text { admission }\end{array}$} & $<1$ Week & 8 & 11.3 & 4 & 5.6 & \multirow{3}{*}{$0.035 *$} \\
\hline & 1 Week- 1 Month & 7 & 9.9 & 2 & 2.8 & \\
\hline & > 1 Month & 3 & 4.2 & 0 & 0 & \\
\hline \multirow[t]{3}{*}{ Cause of admission } & Hypoxia & 12 & 16.9 & 3 & 4.2 & \multirow{3}{*}{$0.023 *$} \\
\hline & Hyperbilirubinemia & 4 & 5.6 & 3 & 4.2 & \\
\hline & Others** & 2 & 2.8 & 0 & 0 & \\
\hline \multirow{2}{*}{$\begin{array}{l}\text { Occurrence of } \\
\text { jaundice }\end{array}$} & No & 40 & 57.7 & 39 & 54.9 & \multirow{2}{*}{0.74} \\
\hline & Yes & 30 & 42.3 & 32 & 45.1 & \\
\hline \multirow{2}{*}{$\begin{array}{l}\text { Congenital } \\
\text { anomalies*** }\end{array}$} & No & 68 & 95.8 & 68 & 95.8 & \multirow{2}{*}{1.00} \\
\hline & Yes & 3 & 4.2 & 3 & 4.2 & \\
\hline \multirow[t]{2}{*}{ Breast feeding } & No & 8 & 11.3 & 4 & 5.6 & \multirow{2}{*}{0.23} \\
\hline & Yes & 63 & 88.7 & 67 & 94.4 & \\
\hline \multirow[t]{2}{*}{ Artificial feeding } & No & 49 & 69 & 60 & 84.5 & \multirow{2}{*}{$0.029 *$} \\
\hline & Yes & 22 & 31 & 11 & 15.5 & \\
\hline
\end{tabular}

"Statistically significant, **Others are like septicemia, prematurity and pneumonia. *** Congenital anomalies are like cardiac anomalies, hypospadias, polydactyl and anal anomalies. 
Table (5): Logistic Regression model for the Factors affecting ASD among studied group:

\begin{tabular}{lcccccc}
\hline & Item & \multirow{2}{*}{ B } & S.E. & P value & Odds ratio & \multicolumn{2}{c}{ 95\% C.I. } \\
\cline { 6 - 8 } & 0.83 & 0.52 & 0.098 & 2.3 & 0.85 & 6.45 \\
\hline Age of father & 0.104 & 0.64 & 0.904 & 1.1 & 0.31 & 3.76 \\
\hline Age of mother & -1.62 & 0.62 & $\mathbf{0 . 0 1 2}$ & 0.21 & 0.06 & 0.71 \\
\hline $\begin{array}{l}\text { Folic acid during } \\
\text { pregnancy }\end{array}$ & 1.53 & 0.70 & $\mathbf{0 . 0 2 5}$ & 4.79 & 1.22 & 18.83 \\
\hline Postnatal hypoxia & 2.01 & 0.81 & $\mathbf{0 . 0 0 9}$ & 8.26 & 1.71 & 39.98 \\
\hline $\begin{array}{l}\text { Positive family history } \\
\text { of psychiatric diseases }\end{array}$ & -4.25 & 1.23 & 0.001 & 0.014 & & \\
\hline Constant & & &
\end{tabular}

